\title{
Chronic tendon pathology: molecular basis and therapeutic implications
}

\section{Graham Riley}

Tendons are frequently affected by chronic pain or rupture. Many causative factors have been implicated in the pathology, which until relatively recently was under-researched and poorly understood. There is now a greater knowledge of the molecular basis of tendon disease. Most tendon pathology (tendinopathy) is associated with degeneration, which is thought to be an active, cell-mediated process involving increased turnover and remodelling of the tendon extracellular matrix. Degradation of the tendon matrix is mediated by a variety of metalloproteinase enzymes, including matrix metalloproteinases and 'aggrecanases'. Neuropeptides and other factors released by stimulated cells or nerve endings in or around the tendon might influence matrix turnover, and could provide novel targets for therapeutic intervention.

Tendons are dense, fibrous connective tissues that connect muscle to bone and are essential for the transmission of force and the generation of movement at a joint. They are highly ordered composite materials consisting of collagens, proteoglycans and various glycoproteins, many of which have been poorly characterised. Tendon problems such as tendon rupture and chronic tendon pain are common, although the underlying pathology is not well understood and the conditions are often difficult to treat (Ref. 1). Terms such as tendonitis (or tendinitis) are traditionally used to describe a painful tendon, the name implying an inflammatory condition. This is contrary to the evidence from most histopathological studies, which describe a degenerative condition without inflammation that has been called tendinosis (Refs 2, 3, 4, 5, 6, 7, 8). In this review, the term tendinopathy is used for all forms of chronic tendon pathology, because it does not assume any knowledge of the underlying pathology.

Factors implicated in tendinopathy It is increasingly recognised that most tendinopathies are not associated with any single factor, and tendon degeneration might result from various causes. Indeed, there is some evidence to suggest that the nature of the degenerative process varies at different sites (Ref. 3). Tendons at certain sites are more commonly affected, particularly the supraspinatus, extensor carpi radialis brevis, patellar and Achilles (at the shoulder, elbow, knee and ankle, respectively) (Refs 9, 10). These tendons

\footnotetext{
Graham Riley

Head of Soft Tissue Injury and Repair Group, Rheumatology Research Unit, Box 194, Addenbrooke's Hospital, Hills Road, Cambridge, CB2 2QQ, UK. Tel: +44 (0)1223 217458; Fax: +44 (0)1223 217838;

E-mail: gpr1003@cam.ac.uk

Institute URL: http: / / www.addenbrookes.org.uk
} 
are all exposed to relatively high mechanical demands, although additional factors are thought to be important. The majority of patients present in late middle age, often with no memory of any acute injury or trauma (Refs 10,11). The condition usually has an insidious onset, with pain developing during or shortly after exercise. Tendon ruptures often occur during physical activity, typically in sports such as badminton (Ref. 12). Many cases of tendinopathy are ascribed to 'overuse', thought to result from repeated microstrain below the failure threshold, analogous to the fatigue failure that affects most materials placed under repetitive loading (Refs 10, 13, 14, 15).

It is generally assumed that tendon damage is the primary event, overwhelming the ability of the tendon cells (generally referred to as tenocytes) to repair structural defects in the tendon extracellular matrix (ECM). Alternatively, there is thought to be a failure to adapt to a change in physical demands. Tenocytes have a central role in the repair and maintenance of the tendon ECM, synthesising new proteins and producing the enzymes that degrade them. This continual process of matrix turnover is normally in balance, and changes in this activity in response to altered patterns of loading, for example, might precede any physical lesion or 'micro-injury'. Aside from microtrauma and hypoxia, factors that could potentially affect the tenocyte activity include age, temperature, drugs and the local activity of biochemical mediators produced by the resident cells. The potential roles of some of these factors are discussed in this review, which emphasises the importance of ECM turnover and matrixdegrading enzymes in tendon health and disease.

\section{The structure and function of tendon}

The principles of tendon structure and function have been comprehensively reviewed elsewhere (Refs 16, 17, 18, 19, 20). In general, tendon consists of successively larger structural units assembled in a highly ordered hierarchy of collagen molecules, microfibrils, subfibrils, fibrils, fibres and fascicles (fibre bundles) (Ref. 21) (Fig. 1). However, tendon is not a homogenous tissue: there are variations in structure and composition between tendons and at specific sites within tendons (Ref. 20).

The best-characterised regional variation within tendon is fibrocartilage, which is found at the insertion or where a tendon bends around a bony prominence or through a fibrous pulley (Refs 20, 22, 23). Fibrocartilage shares some

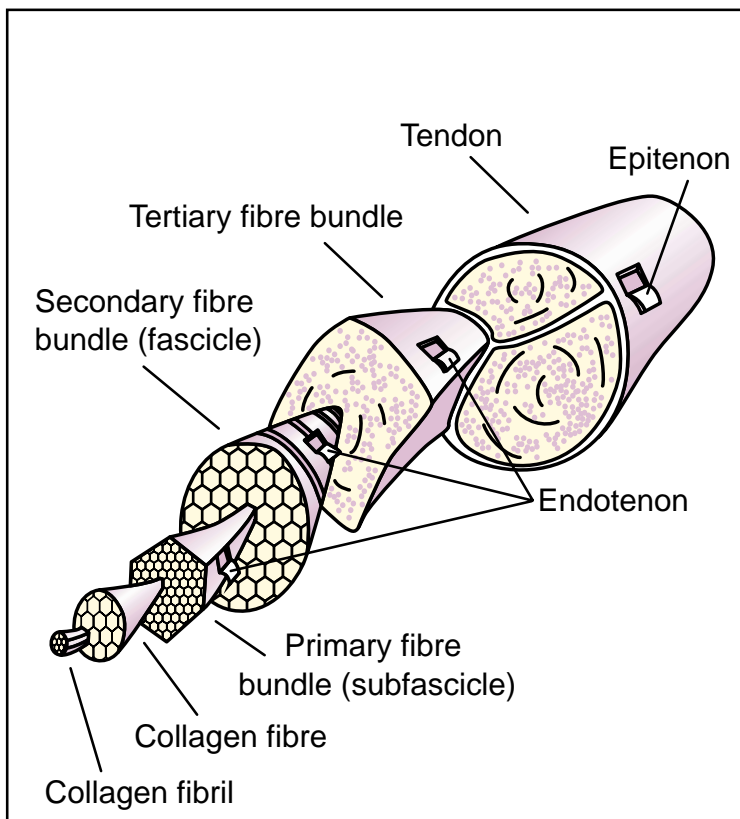

\section{Structure of tendon}

Expert Reviews in Molecular Medicine 2005 Published by Cambridge University Press

Figure 1. Structure of tendon. Tendon consists of a highly ordered hierarchy of successively larger structural units. Collagen molecules aggregate into fibrils, and bundles of fibrils form fibres, many of which are aggregated into primary fibre bundles or subfascicles. Multiple subfascicles form secondary fibre bundles or fascicles, and several fascicles form tertiary fibre bundles. Most tendons consist of multiple fascicles, which is thought to be a fail-safe mechanism so that failure of one or more fibre bundles does not compromise the tendon strength. Fibre bundles are surrounded by a thin layer of connective tissue known as the endotenon, through which pass blood vessels, lymphatics and nerves. The whole tendon is bound by another thin layer (contiguous with the endotenon) known as the epitenon. A loose outer layer known as the paratenon surrounds most tendons (not shown), and some tendons are also surrounded by a specialised synovial sheath. Figure modified from Ref. 21 (@ 1978); reproduced by permission of Taylor \& Francis, Inc., http://www.taylorandfrancis.com.

similarities in structure and composition with articular cartilage, although it also retains essential characteristics of fibrous connective tissue. Its main function is to dissipate shear stress or resist compression, and the fibrocartilaginous region can vary greatly in size depending on factors such 
as the range of movement and the angle of insertion (Refs 24, 25). Fibrocartilage is also thought to play a role in the migration of the insertion during skeletal growth, and to prevent narrowing of the stretched tendon at the interface with bone (Ref. 20).

The cell population in tendon is poorly defined, and there is no single marker of tenocytes (Refs 26, 27). The majority of cells have the appearance of fibroblasts, although there are also chondrocyte-like cells (fibrochondrocytes) within fibrocartilaginous zones, and a small number of capillary endothelial cells, smooth muscle cells and nerve cells, depending on the degree of vascularity and innervation (Ref. 18). There are regional differences in cell morphology and activity within tendons. Synovial-like cells found in the endotenon and epitenon surrounding the main fibre bundles (Ref. 28) possess a greater proliferative capacity and a different matrix- synthesising activity compared with the tenocytes within the fibres, and are the first cells to respond after acute tendon injury (Refs 28, 29, 30, 31, 32). Fibrochondrocytes from the fibrocartilaginous zones synthesise different matrix components (see below), an activity that is stimulated and maintained by the application of compressive load (Refs 33, 34, 35). A small proportion of cells are thought to be mesenchymal stell cells, capable of differentiating into chondrogenic, osteogenic and adipogenic cells when cultured in the appropriate conditions (Ref. 27).

\section{The molecular composition of tendon}

Tendon is a highly ordered composite material consisting predominantly of collagen, with smaller amounts of various proteoglycans and glycoproteins, many of which are relatively poorly characterised (Table 1). Although many

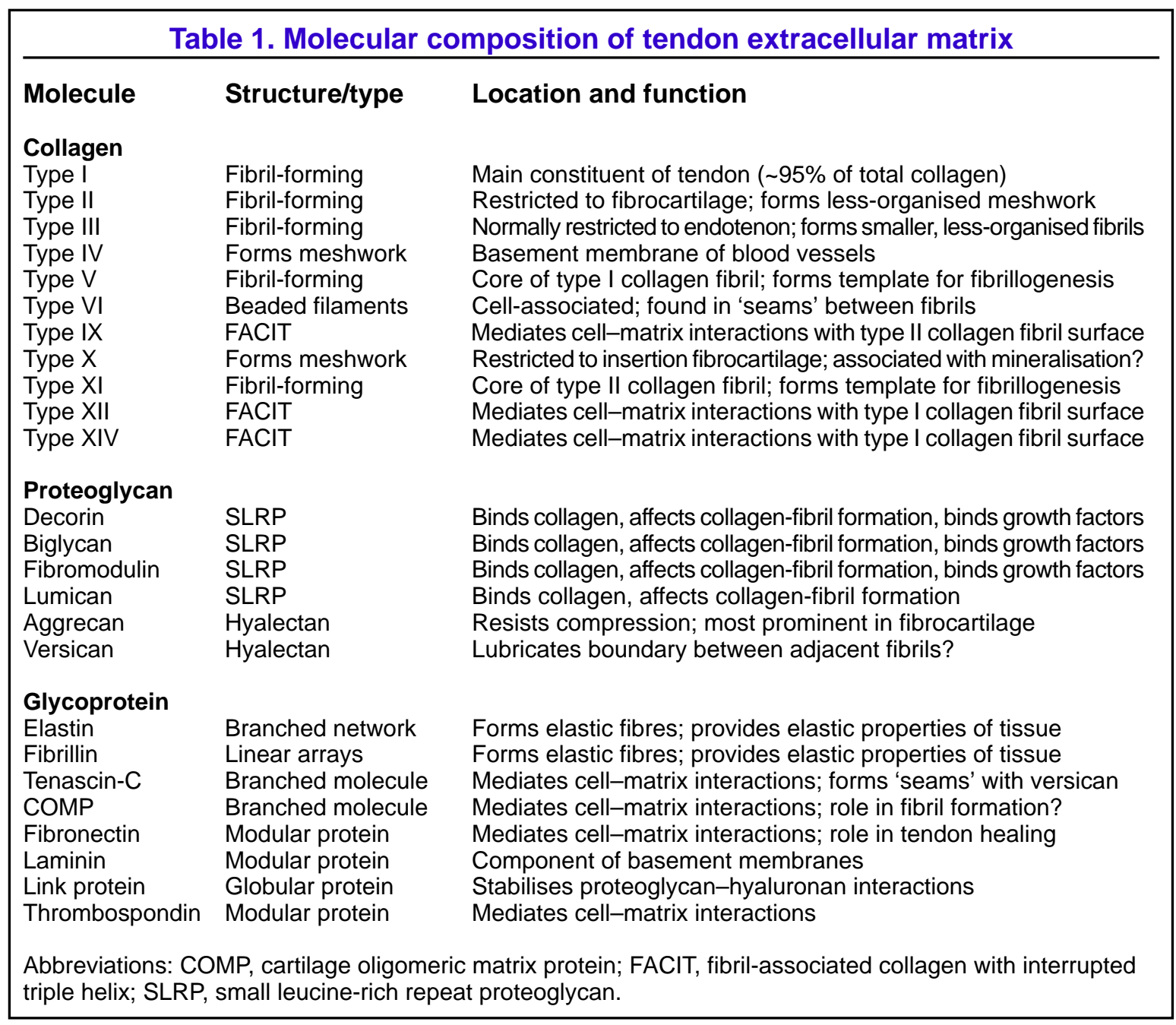


constituents of tendon are present in very small amounts, they have important roles in the ECM, including modulating the formation of fibrils and mediating cell-ECM interactions. It is important to emphasise that the ECM does not merely fulfil a passive, structural role: many of its constituents also have an impact on tenocyte activity. Tendon is not an inert material, as the ECM can be continuously synthesised and replaced throughout life, although the rate of metabolism is much lower than in tissues such as muscle and bone (Ref. 36). There is also evidence of variation in the rate of turnover at different sites and in different tendons (Refs 37,38). This activity is likely to be influenced by both internal and external factors, and is potentially a major factor in the development of tendinopathy.

\section{Collagen}

Extensive reviews of the synthesis, structure and function of collagen, particularly of collagen types I-XIX, have been published elsewhere (Refs 39, 40, 41, 42, 43,44). In brief, each collagen consists of three polypeptide $\alpha$-chains, which combine together as a homotrimer (three identical $\alpha$-chains) or a heterotrimer (with two or three different $\alpha$-chains). To date, 42 vertebrate $\alpha$-chains have been sequenced, several of which can be differentially spliced, and these combine to form at least 27 different collagens (Refs 39, 40, 44). Each $\alpha$-chain forms an extended left-handed helix, and contains a variable length of the repeated amino acid motif Gly-X-Y, where X and Y are commonly proline and hydroxyproline. This amino acid composition is an absolute requirement for the formation of the right-handed triple helix, a defining characteristic of collagenous (COL) protein domains. The collagens also possess globular, noncollagenous (NC) domains of variable size, number and location.

Although all collagens form highly organised polymers, the different collagen types can be grouped according to whether they form fibrils or other structures such as extended sheets or lattices. The classic fibril-forming collagens (types I, II, III, V and XI) comprise a single COL domain for almost the entire length of the molecule, with small NC domains at each end (Fig. 2). The newly discovered collagen types XXIV and XXVII have a similar molecular structure (Refs 45, 46). The nonfibrillar collagens are a heterogenous group with a variety of structures. Collagen types IV, VIII and $X$ form extensive networks, whereas type VI collagen forms beaded microfilaments. Type VII collagen is essentially restricted to basement membranes where it forms anchoring filaments. Several collagens have transmembrane domains, including types XIII, XVII, XXIII and XXV, which mediate interactions between the cell and its external environment. Some collagens, designated FACIT (for 'fibril-associated collagens with interrupted triple helix'), are associated with the surface of fibrils and have several interruptions in the triple-helical structure. Collagen types IX, XII and XIV are the archetypal FACITs, although the more recently described collagen types XVI, XIX, XX, XXI, XXII and XXVI are thought to be related members.

The fibril-forming type I collagen is the major component of tendon; it is generally estimated to represent $95 \%$ of the total collagen, although it is difficult to be precise because of its insolubility, particularly in ageing tendon specimens (Ref. 47). Type III collagen is the next most abundant collagen in tendon, forming around $3 \%$ of the total in human supraspinatus and biceps brachii tendons (Ref. 47). In normal tendon, most type III collagen is found in the endotenon and epitenon (Ref. 48), although it is also found intercalated into the type I collagen fibril bundles, particularly in ageing tendons and at the insertion (Ref. 49). Other minor constituents of tendon are collagen types IV, V, VI, XII and XIV. Collagen types II, IX, $\mathrm{X}$ and $\mathrm{XI}$, once thought to be restricted to cartilage, are found in the fibrocartilaginous regions of tendons and ligaments, where they are presumed to function to help resist compression and shear forces at these sites (Refs 50, 51).

\section{Proteoglycans}

ECM proteoglycans have been classified into two subfamilies: the small leucine-rich repeat proteoglycans (SLRPs) and the large modular proteoglycans. The latter are further divided into two subgroups: those that do not bind hyaluronan; and the 'hyalectans', which bind both hyaluronan and lectin (Refs 40, 52, 53). Only the SLRP and hyalectans are considered in this review, since these are the most abundant proteoglycans in the tendon ECM.

\section{SLRPS}

SLRPs are found in most connective tissues and include decorin, biglycan, fibromodulin and lumican. They all possess a small protein core (36-42 kDa), with an N-terminal domain for 


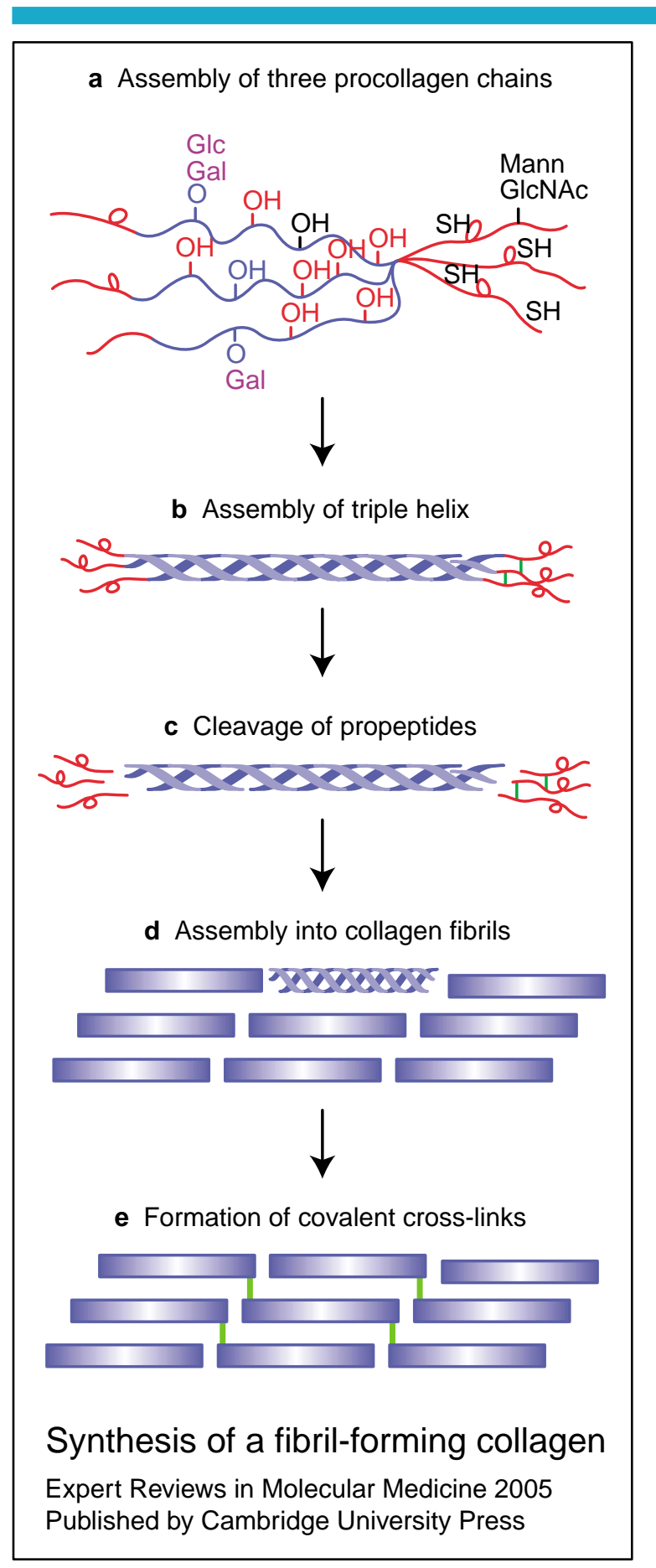

Figure 2. Synthesis of a fibril-forming collagen. (See next column for legend.)

binding of glycosaminoglycan (GAG) chains, a central region of leucine-rich repeats flanked by clusters of cysteines, and a C-terminal domain (Ref. 52) (Fig. 3a). The protein core is compact and horseshoe shaped, which might be important for protein-protein interactions (Ref. 54). SLRPs
Figure 2. Synthesis of a fibril-forming collagen. (a) Following synthesis, the three collagen $\alpha$-chains undergo extensive post-translational modification, including hydroxylation of lysine residues and glycosylation. (b) The $\alpha$-chains wrap around each other to form a tightly wound, right-handed triple helix which is secreted as a procollagen monomer.

(c) The $\mathrm{N}$ - and $\mathrm{C}$-terminal propeptides are cleaved by specific peptidases. (d) The processed collagen forms multimolecular aggregates, which are aligned end-to-end to form banded fibrils. (e) Crosslinks are formed between specific amino acids, which stabilise the collagen fibril and provide tensile strength. Abbreviations: Gal, galactose; Glc, glucose; Mann, mannose; GlcNAc, $\mathrm{N}$-acetylglucosamine; $\mathrm{OH}$, hydroxyl group; $\mathrm{SH}$, sulphydryl group. Figure modified from Ref. 44 (C 2004), with permission from Elsevier.

carry one to four chains of GAG, which can be keratan sulphate (KS), dermatan sulphate (DS) or chondroitin sulphate (CS). The type of GAG depends on the tissue, with decorin containing CS in bone and DS in tendon (Ref. 55). Fibromodulin and lumican have a similar protein core structure to decorin, but contain KS. (Ref. 56).

The most abundant proteoglycan in tendon is decorin, although biglycan is also present in small amounts (Ref. 57). All the SLRPs are now thought to have some role in collagen-fibril formation (fibrillogenesis), acting in a sequential and orchestrated fashion during development and repair to control the growth and ultimate diameter of the collagen fibres (Refs 58,59). Decorin, for example, is found attached to collagen fibres at specific sites every $64-68 \mathrm{~nm}$, where it acts to modulate (limit) collagen-fibril formation (Refs 60,61). Modulation of this activity using antisense gene therapy to inhibit decorin gene transcription has been shown to promote the formation of larger collagen fibrils in healing ligament, thus improving the strength of repair (Ref. 62). Biglycan binds only weakly to type I collagen and has a much greater affinity for type VI collagen, promoting the rapid formation of hexagonal networks (Ref. 63).

Apart from their role in ECM organisation, the SLRPs can also modulate various cell activities (Refs 64, 65, 66). Decorin, fibromodulin and biglycan, for example, might modulate the activity of the resident cell population by binding to and sequestering growth factors such as transforming growth factor $\beta$ (TGF- $\beta$ ) (Refs 65, 66). 
Figure 3. Proteoglycans in tendon. (a) Small leucine-rich repeat proteoglycans (SLRPs). SLRPs in tendon include decorin, biglycan, fibromodulin and lumican. They share a common core protein structure with ten leucine-rich repeats (LRRs) and at least one chain of glycosaminoglycan (GAG). Decorin in tendon has one dermatan sulphate (DS) chain, whereas biglycan has two chondroitin sulphate (CS) chains. Fibromodulin and lumican have up to four keratan sulphate (KS) chains and some tyrosine (Tyr) residues are sulphated. Part a of figure reproduced, with permission, from the Glycoforum website (http://www.glycoforum.gr.jp). (b) Hyalectans. The hyalectans in tendon are versican and aggrecan, with versican predominant in tensileloaded regions and aggrecan in compressed, fibrocartilaginous regions. All hyalectans contain a G1 domain, a GAG-attachment region and a G3 domain that has similarities with selectin. Aggrecan also has a G2 domain, separated from G1 by an interglobular domain (IGD), and the molecule contains approximately $100 \mathrm{CS}$ chains and $30 \mathrm{KS}$ chains. Versican contains up to 21 CS chains, clustered within two GAG domains known as GAG $\alpha$ and GAGB. One or both of the GAG domains might be removed by alternative splicing of the mRNA transcript, forming four versican splice variants.

\section{The 'hyalectans'}

The hyalectan subgroup of large proteoglycans comprises aggrecan, versican, brevican and neurocan (Refs 40,52). Neurocan and brevican are thought to be restricted to brain and neural tissues. The hyalectans possess a large protein core $(100-370 \mathrm{kDa})$ consisting of a C-terminal domain with epidermal growth factor (EGF)-like repeats, a central domain carrying the majority of GAG chains, and an N-terminal hyaluronanbinding domain (Ref. 56) (Fig. 3b).

Aggrecan, the major proteoglycan of articular cartilage but also found in tendon, forms multimolecular aggregates with the nonsulphated GAG hyaluronan. Aggrecan is reported to be present throughout tendon, although it is generally thought to be more abundant in regions of fibrocartilage. Aggrecan has three globular domains (G1, G2 and G3) and contains many GAG chains (CS and KS) attached to specific sites in the GAG-binding domain between the G2 and G3 domains (Ref. 67). The high fixed negative charge of the GAG attracts counter-ions and functions to hold water within the tissue. Swelling of the tendon is restrained by the collagen meshwork, and the resulting turgor functions to resist

Figure 3. Proteoglycans in tendon. (See next column for legend.) 
compressive load. Thus, the expression of aggrecan in compressed regions of tendon, or areas subjected to shear forces such as the insertion, is thought to be a functional adaptation that protects the tissue from damage.

Versican has been identified in many soft connective tissues and has a similar structure to aggrecan, although it lacks a G2 domain and contains much less GAG, all of which is CS (Ref. 68). Its precise role in tendon is unknown, although it is found associated with seams of microfibrils between fibres and it might function to facilitate the sliding of adjacent fibre bundles.

\section{Glycoproteins}

The noncollagenous components of tendon are relatively poorly characterised. Elastin, thought to make up less than $2 \%$ of the tendon dry weight, is a component of the elastic fibres that are thought to maintain the tendon crimp and to be responsible for the elastic properties of the ECM (Refs 13, 69). Fibrillin is also a major component of the elastic microfibril, and is thought to form a template for tropoelastin and the assembly of the elastin multimer (Refs 70, 71). Elastic microfibrils are present in most connective tissues and contain polymers of fibrillin- 1 and fibrillin-2 (Refs 70, 71). Mutations in fibrillin-1 have been linked to Marfan's syndrome and associated disorders of various connective tissues (Ref. 72). Fibrillin-1 is associated with type XVI collagen in the dermis (but not in cartilage), and other proteins such as versican, fibulin, matrix-associated glycoprotein (MAGP)-1, MAGP-2 and emilin (Refs 73, 74, 75, 76). The microfibril structures that are formed have been divided into essentially three types on the basis of structure and appearance - oxytalan, elaunin and elastic - which differ in the relative amounts of elastin (from lowest to highest, respectively). Elastic fibres, predominantly oxytalan, are reportedly more homogenous and abundant in developing tendon, less common in adult tendon and absent from fibrocartilage (Ref. 77).

Fibronectin mediates cell interactions with the ECM, and affects a range of cell functions including cell adhesion, cell migration, differentiation, haemostasis, phagocytosis and chemotaxis (Refs 40,78). Present at low levels in normal tendon, fibronectin is massively increased after tendon injury and consequently has been implicated in cell adhesion, migration and differentiation at the site of injury (Refs 79, 80, 81).
Tenascin- $\mathrm{C}$ is a disulphide-linked hexameric protein with subunits of 200-300 kDa in humans, created by alternative splicing of a single gene transcript (Refs 82, 83). In normal fibrous tendon, tenascin-C might have a role in maintaining the interface between fibrils and adjacent structures (Ref. 84). In fibrocartilaginous regions of tendon, tenascin-C is predominantly cell-associated (similar to type VI collagen) and is implicated in the development of the chondrocyte cell phenotype (the expression of type II collagen and aggrecan) in response to compressive load (Ref. 84). Tenascin-C is transiently increased after tendon injury, and is thought to modulate cell activities in the developing scar (Refs 85, 86).

Cartilage oligomeric matrix protein (COMP), despite its name, is not restricted to cartilage and is a major component of tendon, representing up to 3\% of the dry weight (Ref. 87). A member of the thrombospondin gene family (thrombospondin 5), it is a large $(524 \mathrm{kDa})$ pentameric molecule composed of five disulphide-bonded subunits (Ref. 88). Like tenascin-C and the other thrombospondins, it is thought to have both a structural role and an interactive role with the cell population. There is a strong positive correlation of COMP expression with the levels of mechanical load, with higher levels in flexor tendons compared with extensors (Ref. 89). Levels of COMP increase with age up to skeletal maturity, although only in weight-bearing tendons (Ref. 89). The structural importance of COMP is shown by the condition of pseudoachondroplasia, a genetic disorder caused by a mutation in the COMP gene, resulting in short stature, lax joints and early-onset osteoarthritis (Ref. 90).

In addition to serum proteins such as albumin, other glycoproteins in tendon include: laminin, which is found as a major constituent of basement membranes; link protein, which stabilises hyalectan-hyaluronan interactions (Refs 6, 91); and other multidomain adhesive glycoproteins, including members of the thrombospondin family, that, like COMP, tenascin and fibronectin, mediate cell-matrix interactions in normal and injured tissues (Refs 92, 93, 94).

\section{The molecular pathology of chronic tendinopathy}

Histopathological studies of tendinopathy have shown an absence of inflammatory cell infiltration and the presence of many features thought to be characteristic of ECM degeneration. These include 
a loss of fibre organisation, decreased fibril diameter, changes in cell density (both increased and decreased), cell rounding, GAG accumulation, lipid accumulation and calcification (Refs 3, 4, 5, 7, 95) (Fig. 4). Although similar changes are commonly found in normal tendons, they are generally less severe, and it is assumed that ECM degeneration precedes the onset of the clinical condition (Refs 3, 7, 96).

There have been few biochemical studies of chronic tendinopathy. In ruptured supraspinatus tendons there was a small but significant decrease in the total collagen content, and an increased proportion of type III collagen relative to type I collagen (Ref. 47). The collagen had a high content of hydroxylysine and there were greater than normal levels of the mature collagen crosslinks hydroxylyslpyridinoline (HP) and lysylpyridinoline (LP) (Ref. 97). These and other crosslinks greatly affect the solubility of the collagen, making it difficult to assess the collagen type, even using chemical methods such as cyanogen bromide peptide mapping. However the changes in the tendon ECM are characteristic of scar tissue, and the levels of type III collagen and HP tend to diminish as healing proceeds, although high levels often persist because of incomplete remodelling (Ref. 98). Similar ECM
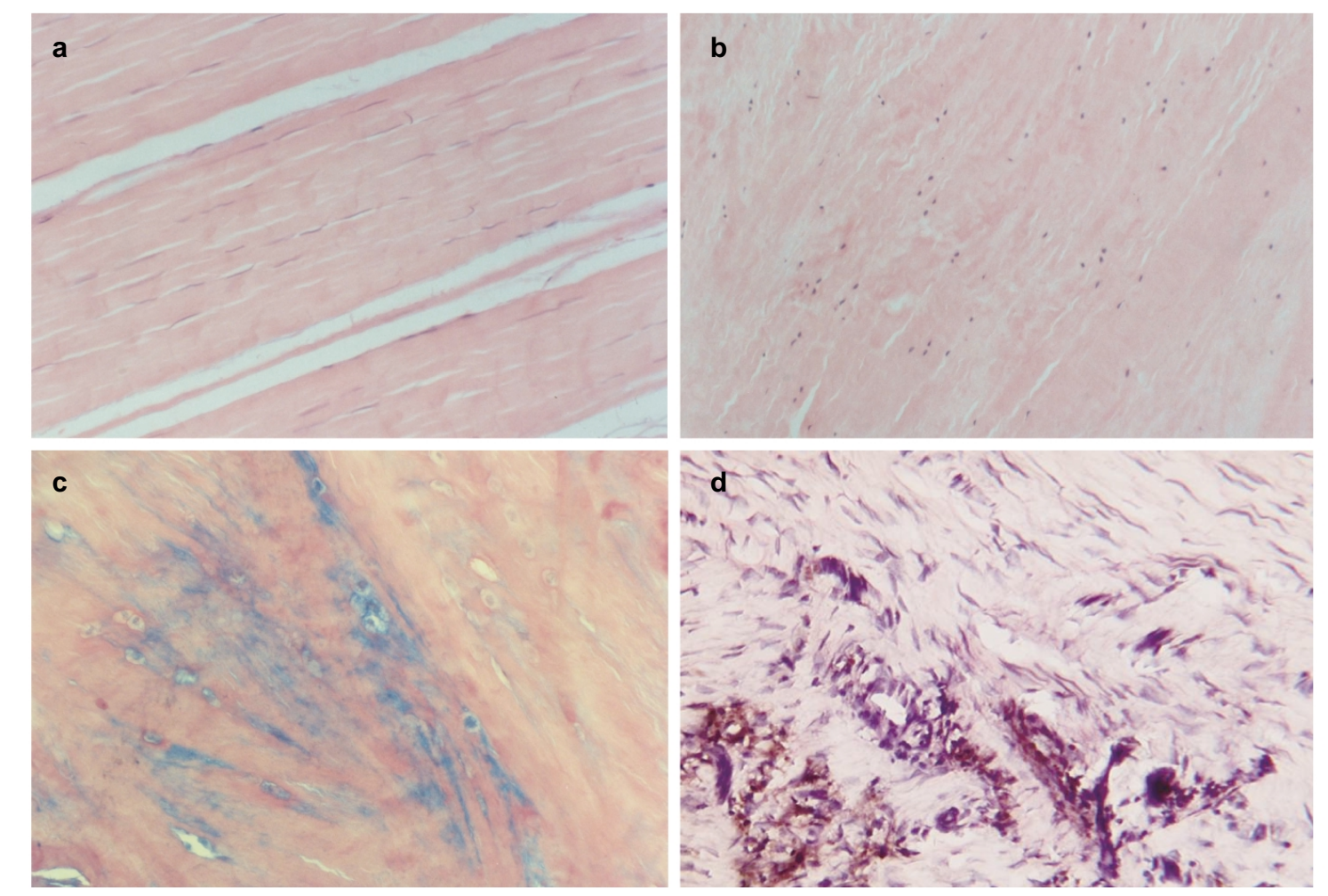

\section{Histopathology of tendinopathy}

Expert Reviews in Molecular Medicine ๑2005 Cambridge University Press (parts a, b and d only)

Figure 4. Histopathology of tendinopathy. (a) Normal flexor tendon histology, showing organised parallel fibre bundles and long thin tenocytes dispersed throughout the matrix [stained with hematoxylin and eosin (H\&E)]. (b) Ruptured supraspinatus tendon, showing hyaline (glassy) appearance, loss of matrix organisation and rounded, shrunken nuclei (H\&E). (c) Glycosaminoglycan (GAG) accumulation ('mucoid degeneration') in supraspinatus tendon, showing GAG (blue) surrounding rounded cells in the matrix (Alcian Blue and H\&E). (d) 'Angiofibroblastic' change in painful Achilles tendinopathy, showing increase in cell number and blood vessels (H\&E). Part c of figure reprinted from Ref. 4 (C 1994); reproduced with permission from the BMJ Publishing Group. 
changes have since been reported in studies of posterior tibialis tendon dysfunction and Achilles tendon rupture (Refs 99, 100). These data are consistent with the gradual accumulation of type III collagen over a relatively long time period, allowing the maturation of collagen crosslinks and stabilisation of the ECM. The gradual incorporation of type III collagen into the main fibre bundles is consistent with a reduction in the average fibril diameter (Ref. 101), a change that is thought to weaken the tendon and to precede tendon rupture (Ref. 102).

Other biochemical studies have shown an increase in the amount of hyaluronan and various proteoglycans in degenerate tendons, although the latter have not yet been fully characterised (Refs 103, 104). An increased water content, typically $10 \%$ above normal, is commonly found in tendinopathy, associated with the increased proteoglycan content. Consequently, the specimen dry weight or collagen (hydroxyproline) content is a better reference point for composition studies than the tissue wet weight. Differences in the sugar moieties expressed in ruptured tendons compared with normal were revealed by changes in lectin-staining properties (Ref. 105). Glycoproteins such as tenascin-C were increased in ruptured supraspinatus, with different protein isoforms expressed as well as numerous small peptide fragments, the latter consistent with enzyme-mediated cleavage in the tissue (Ref. 84). Fibronectin immunostaining was significantly increased in ruptured tendon, and there was accumulation of necrotic tissue and fibrin (Ref. 106).

Several studies have shown differences in the expression of various genes encoding matrix proteins in tendinopathy (Refs 107, 108, 109). In one study, for example, 23 genes were found to be upregulated and 17 genes were downregulated in degenerate Achilles tendon (Ref. 107). Although potentially very informative, relatively few of these changes have been confirmed by more rigorous techniques, and the levels of cognate proteins for many of these genes have not been investigated. There were no changes detected in the expression of cytokines and cytokine receptors, consistent with the absence of any ongoing inflammatory process, as confirmed by an analysis of the fluids surrounding painful tendons (Ref. 110). However, these data do not rule out the involvement of inflammation at earlier stages of the disease. It is possible, for example, that the tendon fails to recover after the inflammatory reaction has subsided.

In summary, the ECM changes described in chronic tendinopathy are consistent with a cellmediated remodelling process occurring in degenerate tendon, without inflammation. The process is similar in many respects to the later stages of a wound-healing response, albeit with impaired or incomplete remodelling, rather than any functional adaptation. The evidence generally supports the hypothesis that there is gradual deterioration in the quality of the ECM, which predisposes to tendon pathology. A key element of this process is thought to be the cellular expression of proteolytic activities and their effects on tendon ECM turnover.

\section{Role of MMPs in tendon collagen degradation and tendinopathy}

Proteolytic activity is an essential component of tissue maintenance and repair. After injury, proteolysis is required to remove any damaged ECM and remodel the newly formed scar so that it more closely resembles the normal tissue. Some collagen in tendon is probably degraded intracellularly after phagocytosis, with fibroblasts and macrophages engulfing collagen molecules that are then digested by lysosomal enzymes, comprising mainly cysteine and aspartate proteases (Refs 111, 112). This is a major activity in the rapidly remodelling peridontal ligament, although few (if any) studies have investigated the function of lysosomal enzymes and serine proteases in tendon matrix turnover. Most published studies have focused on collagen degradation occurring in the extracellular environment and mediated by secreted metalloenzymes known as the MMPs.

\section{MMPs: a brief overview}

Comprehensive reviews of the MMPs have been published elsewhere and only salient points are reviewed here (Refs 113, 114, 115, 116, 117, 118, $119,120)$. MMPs are members of the 'MB' clan of metallopeptidases, generically referred to as 'metzincins' because they contain zinc at the active site and a conserved methionine eight residues downstream. There are $23 \mathrm{MMPs}$ found in humans, each comprising a multidomain structure and with activity at neutral $\mathrm{pH}$ against a broad spectrum of different ECM substrates (Refs 114, 116, 118) (Table 2; Fig. 5a). Although important in ECM degradation, MMPs also have 
activity against cell-surface receptors and growth factor precursors (Ref. 119). Consequently, these enzymes also have an important role in the regulation of numerous cellular activities including cell proliferation, cell death (apoptosis), cell migration and chemotaxis (Ref. 119).

The activities of MMPs are normally tightly controlled in vivo, with regulation at the levels of gene transcription, protein translation, activation and inhibition. In general, expression and activity of the MMPs is stimulated by pro-inflammatory cytokines such as interleukin 1 (IL-1) and tumour necrosis factor (TNF), and is inhibited by growth factors such as TGF- $\beta$. MMPs are potently inhibited by $\alpha_{2}$-macroglobulin in the serum, and also by a family of specific inhibitors produced by cells within the tissues known as tissue inhibitors of metalloproteinases (TIMPs) (Refs 115, 116, 121). Four TIMPs have been characterised to date, and each TIMP binds to active MMPs in a stoichiometric (1:1) ratio, resulting in a stable, inactive complex. 
Figure 5. Domain structure of matrix metalloproteinases (MMPs) and ADAMTS. (a) MMPs. The archetypal MMPs such as the collagenases and stromelysins share common domains: a signal peptide that is cleaved prior to synthesis, a propeptide that renders the enzyme inactive until removed by proteolysis, a catalytic domain with a zinc-binding site, a hinge region, and a haemopexin domain that confers substrate specificity. Gelatinases have an additional, gelatin-binding domain consisting of fibronectin type II repeats. Other MMPs have additional domains (not shown, but see Ref. 120). (b) ADAMTS. The ADAMTS family share a common domain structure, with a prodomain that is cleaved within the cell to activate the enzyme, a metalloproteinase catalytic domain, a disintegrin domain, a cysteine (Cys)-rich domain and a variable number of thrombospondin (TS) type I repeats. Several additional C-terminal domains have been found downstream of the variable TS type 1 repeats in some ADAMTS molecules (not shown, but see Ref. 120). Modified figure reproduced from Ref. 120, published in this journal.

\section{MMPs in tendon}

The MMPs are implicated in both the physiological and pathological turnover of the tendon ECM. Pieces of normal tendon placed in explant culture produce collagenase and gelatinase activities, degrading the collagen matrix after two to three weeks in culture, and this process is stimulated by the addition of inflammatory cytokines such as IL-1 (Refs 122, 123, 124, 125). MMPs are also implicated in the remodelling of tendon that follows immobilisation (Refs 126, 127, 128, 129). MMP-1 is thought to be one of the key mediators of tendon fibrillar collagen degradation, at least in explant culture, and this activity can be inhibited by the application of cyclical strain, an effect though to be mediated via the tenocyte cytoskeleton (Refs 130, 131, 132, 133, 134). Isolated tenocytes respond to strain and shear forces by 
upregulation of MMP, demonstrating that mechanical strain is likely to be a major stimulus for ECM remodelling in tendon (Refs 135, 136). MMP expression was stimulated in rabbit tendon in vivo by extended periods of cyclical loading, although there was no sign of injury as assessed by histological examination (Ref. 137). Intense physical training was also shown to increase MMP-2 and MMP-9 activities in the fluid surrounding human Achilles tendon (Ref. 138).

Several MMPs have been identified in acute tendon injuries, with differences in the timing and location of expression that suggest different roles in the healing process. Levels of MMP-9 and MMP-13 peaked 7-14 days after injury, whereas MMP-2, MMP-3 and MMP-14 increased and were maintained at high levels until at least day 28 (Ref. 139). Thus, it appears that MMP-9 and MMP-13 are involved in the degradation of collagen in the initial inflammatory phase, whereas MMP-2, MMP-3 and MMP-14 have a role in the remodelling of the scar tissue.

A comparison of human tendons showed evidence of substantial differences in the rate of collagen turnover between tendons from different sites (Ref. 38). There was very little collagen turnover in normal biceps brachii tendons, which contained no significant levels of MMP activity and a linear accumulation of pentosidine crosslinks with increasing age (Ref. 38). By contrast, supraspinatus tendons obtained from normal shoulders showed relatively high levels of collagen turnover, and there were correspondingly high levels of MMP-1, MMP-2 and MMP-3 activity (Ref. 38). In ruptured supraspinatus tendon, there was increased activity of MMP-1, reduced activity of MMP-2 and MMP-3, and evidence of increased turnover of the collagen network (Ref. 38). Levels of expression of MMP-1 and MMP-3 in shoulder fluids were shown to correlate with the size of the tendon tear, and MMP-1 was expressed by cells within the ruptured tendon (Refs 140, 141).

Studies of painful Achilles tendons using cDNA arrays have identified several differences in MMP gene expression, although many of these findings need to be confirmed by RT-PCR analysis (Refs 107, 108). The absence of MMP-1 and MMP-8 expression was consistent with an absence of inflammation, and there was a small but variable increase in MMP-2 and MMP-14 in degenerate tendons, whereas MMP-9 and MMP-13 were detected only in ruptured tendons (Refs 107,108 ).
The greatest difference between normal and pathological tendon specimens was the level of MMP-3, which was absent or significantly less abundant in painful tendinopathy (Refs 107, 108). A similar change was reported in degenerate supraspinatus tendons (Ref. 38), consistent with a role for MMP-3 in the maintenance of the normal tendon ECM, at least in highly stressed tendons such as the supraspinatus and the Achilles. The loss of MMP-3 activity in tendinopathy could account for the increase in proteoglycan commonly found in tendon lesions, since proteoglycans are potential substrates for the enzyme. However, since most proteoglycan degradation in vivo is attributed to aggrecanases (see below), more research is required to identify the role of MMP-3 in tendon.

\section{Role of aggrecanases in tendon proteoglycan degradation and tendinopathy}

Proteoglycans are turned over much more rapidly than the fibrillar collagens. Although some members of the MMP family, for example MMP-3, can degrade proteoglycans such as aggrecan in vitro, most proteoglycan-degrading activity in vivo is associated with a related but distinct group of metallo-endopeptidases, commonly known as aggrecanases.

Aggrecanases were first identified on the basis of their ability to cleave aggrecan at specific GluXaa bonds. The core protein is cleaved at several sites, resulting in the shortening of the core protein or the complete loss of the GAG-rich portion of the molecule from the tissue (Ref. 142). This activity was associated with the loss of cartilage proteoglycan that accompanies osteoarthritis (Ref. 143). Aggrecanases were subsequently identified as members of the ADAMTS family, a subgroup of ADAM (for 'a disintegrin and metalloproteinase') with thrombospondin (TS) type I motifs (Refs 144, 145) (Fig. 5b).

\section{Aggrecanases and the ADAMTS family}

To date, 19 mammalian ADAMTS enzymes have been identified, many of which are not yet fully characterised (Refs 144, 145). ADAMTS-2, ADAMTS-3 and ADAMTS-14 are procollagen peptidases, and function as regulators of collagenfibril assembly (Refs 146, 147, 148). ADAMTS-4 (aggrecanase 1) and ADAMTS-5 (aggrecanase 2) were the first aggrecanases to be identified (Refs 144, 149, 150), although ADAMTS-1 and other 
phylogenetically related enzymes (ADAMTS-8, ADAMTS-9, ADAMTS-15 and ADAMTS-20) might also have aggrecanase activity (Refs 151, $152,153,154)$. Best known for their activity against aggrecan, ADAMTS- 1 and ADAMTS- 4 are also capable of cleaving other ECM proteoglycans such as versican and brevican (Ref. 155), and glycoproteins such as COMP (Ref. 156), at least in vitro. Although inhibition of ADAMTS-4 and ADAMTS- 5 can prevent cartilage degradation in tissue culture models (Ref. 157), the enzymes responsible for proteoglycan degradation in osteoarthritis and other diseases of connective tissues have yet to be identified.

Aggrecanase activity is thought to be regulated at multiple levels, although the mechanism is currently poorly understood. Differential regulation of ADAMTS mRNAs has been deduced from analysis of their expression in cell and explant cultures, albeit with considerable variation between studies (Refs 157, 158, 159, 160, 161). A study of human tendon cells has reported small and variable effects of IL-1 on ADAMTS-4 expression (Ref. 161).

In addition to regulation at the level of gene transcription, the activities of ADAMTS enzymes are also subject to post-translational regulation. The noncatalytic ancillary domains of ADAMTS- 4 are required for both catalytic activity and substrate specificity (Refs 162, 163). Full-length enzyme is sequestered in the ECM via GAGbinding sequences in the spacer domain, and sulphated GAGs attached to the aggrecan core protein are required for ADAMTS- 4 activity (Ref. 163). Deletion of the C-terminal spacer domain increased the efficiency of hydrolysis of aggrecan at Glu373-Ala374 bonds, and revealed new activities against fibromodulin, decorin and a general protein substrate (Ref. 163). Several short forms of ADAMTS-4, thought to be generated by autocatalytic C-terminal truncation, are found in cartilage, and these potentially contribute to the degradation of a broad range of protein substrates in addition to proteoglycans (Refs 162, 163). The enzymes are thought to be secreted in an active form after cleavage of the prodomain within the cell by furin, which might be followed by C-terminal truncation by MMP-17 at the cell surface (Refs 164, 165). Aggrecanases such as ADAMTS-4 are inhibited by the general proteinase inhibitor $\alpha_{2}$-macroglobulin and by the specific endogenous inhibitor TIMP-3, but not by other TIMPs (TIMP-1, -2 and -4) (Ref. 166).

\section{Aggrecanase activities in tendon}

Studies of normal (bovine) tendon have shown that proteoglycans are constitutively turned over relatively rapidly, with hyalectans breaking down more rapidly than the SLRPs (Refs 167, 168, 169). Proteolytic fragments of proteoglycans such as aggrecan were present in both young and mature tendon, in both tensional and compressed regions. Much of the aggrecan in tendon appears to lack the G1 domain, but the molecule might be retained in the tissue by interactions of the G3 domain with an unidentified matrix component. Cultured tendon explants released cleavage products into the culture medium and there was no significant stimulation of this activity by IL-1 (Ref. 167). There was no evidence of MMPmediated proteoglycan turnover, although aggrecan turnover did not directly correlate with the levels of expression of either ADAMTS-4 or ADAMTS-5 mRNA. However, gene expression might play a relatively minor role in the regulation of aggrecanase activity, and further studies are required to identify the enzyme activities present in human tendon and their role in tendinopathy. Since levels of proteoglycan are increased in the degenerate tendon lesion (unlike osteoarthritic cartilage), it will be interesting to determine whether this is caused by an increase in proteoglycan synthesis or a decrease in proteoglycan degradation.

\section{Clinical implications \\ Anti-inflammatory drugs: do they have a role in the treatment of tendinopathy?}

The absence of inflammatory cells, at least at later stages of the disease, would suggest that there is no rational basis for the treatment of chronic tendinopathy with anti-inflammatories such as nonsteroidal anti-inflammatory drugs (NSAIDs) and corticosteroid injections, both of which are commonly used even though there are limited data to demonstrate their effectiveness (Ref. 1). However, it has recently been argued that the definition of inflammation should be reappraised, since inflammatory mediators can be produced by a variety of cell types, and not just by infiltrating leukocytes (Ref. 170). Degenerative conditions such as osteoarthritis can be considered inflammatory diseases on this basis, with the expression of cytokines and nitric oxide by chondrocytes and / or synovial cells (Refs 170, 171, 172). In a similar fashion, it is possible that mediators of inflammation might be involved in 
chronic tendinopathy, although produced by the resident cell population or surrounding connective tissues (Refs 173, 174, 175, 176). For example, prostaglandins and other inflammatory mediators were found to be increased in the fluids surrounding tendons following vigorous exercise and are implicated at least in the adaptive response of the tissue (Refs 177, 178, 179). Increased expression of the inducible cyclooxygenase (COX-2) in patellar tendinosis suggests some involvement of prostaglandins in the disease (Ref. 175). Several studies have shown IL-1 was more abundant in the endotenon, vascular endothelium and synovial tissues surrounding affected tendons (Refs 174, 176). Inflammatory mediators might also be transiently produced by the tenocytes, which can be induced to express IL-1 $\beta$ and COX-2 under the influence of mechanical strain, providing a theoretical basis for the development of 'overuse' tendinopathy (Refs 180, 181, 182, 183). However, most molecular studies of tendinopathy have so far provided no conclusive evidence for the involvement of inflammatory mediators and cytokines such as prostaglandin $\mathrm{E}_{2}$ and IL-1 (Refs 107, 108, 184, 185).

\section{Enzymes as potential targets for therapy}

In degenerative conditions such as osteoarthritis, one of the targets for drug therapy is the increased cartilage ECM degradation mediated by enzymes such as MMPs and ADAMTS (Refs 118, 186). Various therapeutic approaches have been attempted, including selective inhibition of collagenases or broad-spectrum inhibition of many different MMPs, although none has yet been successful in clinical trials (Ref. 118).

The pathology of tendinopathy is evidently different from osteoarthritis, with increased cell activity, neovascularisation, and accumulation of proteoglycan within the lesion, in addition to increased turnover of the matrix collagen. Indeed, it would appear that some ECM turnover is required for maintaining the health of the tendon, at least in highly stressed tendons such as the supraspinatus and Achilles. This hypothesis is consistent with data obtained from clinical trials with broad-spectrum MMP inhibitors, which were found to cause an unwanted side effect described as a 'musculo-skeletal syndrome' in the tendons of the patients' shoulders and hands, which recovered after the cessation of therapy (Refs 187, 188). Compounds selective for collagenases or gelatinases did not induce the condition, and the precise cause of the syndrome remains unidentified. Additional activity against 'sheddases' (members of the ADAM family of metalloproteases involved in the processing of cell-surface receptors) might explain the development of the syndrome, although there is no consensus of opinion. Because there are many different enzymes, a solution to this problem will require an analysis of all the metalloproteinase enzymes that are expressed and active in healthy and degenerate tendon.

\section{Neuropeptides and tendon ECM turnover: a novel therapeutic target for tendinopathy?} If inflammation is not associated with the development of chronic tendinopathy, other causes of tendon pain and ECM degeneration must be considered. Recent studies have suggested that nerves, and small peptides ('neuropeptides') produced by nerve endings, might have a role in tendinopathy, similar to that described in intervertebral disc degeneration (Refs 189, 190).

In studies of 'tennis elbow' lesions, nerve endings and neuropeptides were found at the site of the lesion, although it was unclear if this distribution was different to normal (Ref. 191). Studies of fluids obtained from around painful tendons using a microdialysis technique have shown that levels of the neurotransmitter glutamate were significantly increased in tendinopathy relative to controls (Refs 110, 184, 192). Both free glutamate and glutamate receptors (NMDAR1) have also been detected within Achilles tendons, located to nerve fibres, both in tendinopathy specimens and in controls (Ref. 193). Since glutamate is a potent mediator of pain in the central nervous system, it was suggested that NMDAR1 antagonists might be useful in the treatment of tendon pain.

It has also been reported that substance $\mathrm{P}$, another neuropeptide associated with the sensation of pain, is increased in the subacromical bursa in patients with rotator cuff tendinopathy (Ref. 194). The amount of substance P was shown to correlate with the degree of motion pain as assessed by a visual analogue scale. Whether this was due to an increase in the release of substance $\mathrm{P}$ or an increase in the number of nerve fibres was not clear, although immunohistochemistry showed more nerve fibres in bursal tissues of patients with a perforated rotator cuff (Ref. 194). Apart from the modulation of pain, substance $\mathrm{P}$ and other 
neuropeptides might have additional effects, regulating the local circulation and stimulating neurogenic inflammation in and around the tendon (Refs 195, 196).

Hart et al. have proposed that regulatory units composed of nerve endings and mast cells reside in and around the tendon (Ref. 197). The release of neurotransmitters stimulates mast-cell degranulation, releasing a variety of mediators including growth factors that influence oedema, angiogenesis, fibroblast proliferation and many other aspects of cell activity. Biomechanical stimulation of these nerve-mast-cell units might form part of the normal regulatory system, maintaining the tissue and also contributing to the adaptive response to load. Excessive stimulation of neural-mast-cell units might contribute to overuse tendinopathy. Since the extent of innervation and vascularisation varies between different tendons, the potential for the development of neurogenic dysfunction also varies. This theory potentially links mechanical stimulation of the paratenon, which is more richly innervated, and tissue changes in the tendon mid-substance. The association of neuropeptides with tissue remodelling has not been conclusively proved, although substance $\mathrm{P}$ and calcitonin-gene-related peptide (CGRP) were shown to modulate directly the expression of MMP-1 and MMP-3, at least in vitro (Refs 195, 198). Thus innervation, and the stimulation of neuropeptide release by strain or friction at the tendon surface, is thought to be important for both normal tendon function and tendinopathy, affecting remodelling events in the tissue. Since peptide antagonists of substance $\mathrm{P}$ are already available, having been used in clinical trials for the treatment of pain, emesis and depression, it is possible that they could prove useful for the treatment of chronic tendinopathy.

\section{Concluding remarks}

Most tendinopathy is associated with degeneration, which is thought to be an active, cell-mediated process involving increased turnover and remodelling of the tendon ECM. There is a gradual transformation in the quantity and quality of the ECM that precedes tendon rupture. However, some ECM turnover might be required to maintain the health of the tendon, particularly at sites exposed to high mechanical strain, such as the shoulder and ankle. Degradation of the tendon ECM is mediated by a variety of metalloproteinase enzymes, including MMPs and aggrecanases. Some enzymes are thought to be responsible for repair and maintenance of the tendon, and others are implicated in the pathological destruction of the ECM: these enzymes need to be identified so that new drugs can be developed. There are a variety of factors that might influence ECM turnover in tendon, although a major factor in most tendinopathy is thought to be repeated minor mechanical strain or 'overuse'. Although infiltrating inflammatory cells are probably not involved in chronic tendinopathy, neuropeptides and other mediators of pain and inflammation produced in or around the tendon might be implicated, and could provide novel targets for therapeutic intervention.

\section{Acknowledgements and funding}

The author is grateful for financial support from the Arthritis Research Campaign, The Isaac Newton Trust, REMEDI, The Wishbone Trust, The Dunhill Medical Trust, The Sybil Eastwood Trust and the Cambridge Arthritis Research Endeavour (CARE). Acknowledgements are due to many past and present members of the Rheumatology Research Unit, in particular Dr Brian Hazleman, Professor Tim Cawston, Dr Michael Chard, Dr Steven Fenwick, Dr Anthony Corps, Mrs Val Curry and Ms Rebecca Harrall. Thanks also to the surgeons who have provided human tendon specimens, including Mr Chris Constant, $\mathrm{Mr}$ Andrew Robinson, Mr Roger Hackney and Mr Graham Holloway.

\section{References}

1 Almekinders, L.C. and Temple, J.D. (1998) Etiology, diagnosis, and treatment of tendonitis: an analysis of the literature. Med Sci Sports Exerc 30, 1183-1190, PubMed: 9710855

2 Puddu, G., Ippolito, E. and Postacchini, F. (1976) A classification of Achilles tendon disease. Am J Sports Med 4, 145-150, PubMed: 984291

3 Kannus, P. and Jozsa, L. (1991) Histopathological changes preceding spontaneous rupture of a tendon. A controlled study of 891 patients. J Bone Joint Surg Am 73, 1507-1525, PubMed: 1748700

4 Chard, M.D. et al. (1994) Rotator cuff degeneration and lateral epicondylitis: a comparative histological study. Ann Rheum Dis 53, 30-34, PubMed: 8311552

5 Astrom, M. and Rausing, A. (1995) Chronic Achilles tendinopathy. A survey of surgical and histopathologic findings. Clin Orthop 151-164, 
PubMed: 7634699

6 Jarvinen, M. et al. (1997) Histopathological findings in chronic tendon disorders. Scand J Med Sci Sports 7, 86-95, PubMed: 9211609

7 Riley, G.P., Goddard, M.J. and Hazleman, B.L. (2001) Histopathological assessment and pathological significance of matrix degeneration in supraspinatus tendons. Rheumatology (Oxford) 40, 229-230, PubMed: 11257166

8 Khan, K.M. et al. (2002) Time to abandon the "tendinitis" myth. Bmj 324, 626-627, PubMed: 11895810

9 Leadbetter, W.B. (1992) Cell-matrix response in tendon injury. Clin Sports Med 11, 533-578, PubMed: 1638640

10 Józsa, L. and Kannus, P. (1997) Overuse injuries of tendons. In Human Tendons: Anatomy, Physiology and Pathology (Józsa, L. and Kannus, P., eds), pp. 164-253, Champaign, IL

11 Kannus, P. (1997) Etiology and pathophysiology of chronic tendon disorders in sports. Scand J Med Sci Sports 7, 107-112, PubMed: 9211611

12 Fahlstrom, M., Lorentzon, R. and Alfredson, H. (2002) Painful conditions in the Achilles tendon region: a common problem in middle-aged competitive badminton players. Knee Surg Sports Traumatol Arthrosc 10, 57-60, PubMed: 11819023

13 Butler, D.L. et al. (1978) Biomechanics of ligaments and tendons. Exerc Sport Sci Rev 6, 125-181, PubMed: 394967

14 Ker, R.F., Wang, X.T. and Pike, A.V. (2000) Fatigue quality of mammalian tendons. J Exp Biol $203 \mathrm{Pt}$ 8, 1317-1327, PubMed: 10729280

15 Ker, R.F. (2002) The implications of the adaptable fatigue quality of tendons for their construction, repair and function. Comp Biochem Physiol A Mol Integr Physiol 133, 987-1000, PubMed: 12485688

16 Oakes, B. (1994) Tendon-ligament basic science. In Oxford Textbook of Medicine (Harries, M. et al., eds), pp. 493-511, Oxford University Press, Oxford

17 Józsa, L. and Kannus, P. (1997) Functional and mechanical behaviour of tendons. In Human Tendons: Anatomy, Physiology and Pathology (Józsa, L. and Kannus, P., eds), pp. 98-113, Champaign, IL

18 Józsa, L. and Kannus, P. (1997) Structure and metabolism of normal tendons. In Human tendons: anatomy, physiology and pathology (Józsa, L.and Kannus, P., eds), pp. 46-95, Champaign, IL,
19 Kannus, P. (2000) Structure of the tendon connective tissue. Scand J Med Sci Sports 10, 312320, PubMed: 11085557

20 Benjamin, M. (2004) The structure and function of tendons. In Soft Tissue Rheumatology (Hazleman, B.L., Riley, G.P. and Speed, C.A., eds), pp. 9-19, Oxford University Press, Oxford

21 Kastelic, J., Galeski, A. and Baer, E. (1978) The multicomposite structure of tendon. Connect Tissue Res 6, 11-23, PubMed: 149646

22 Cooper, R.R. and Misol, S. (1970) Tendon and ligament insertion. A light and electron microscopic study. J Bone Joint Surg Am 52, 1-20, PubMed: 4189231

23 Benjamin, M., Evans, E.J. and Copp, L. (1986) The histology of tendon attachments to bone in man. J Anat 149, 89-100, PubMed: 3693113

24 Evans, E.J., Benjamin, M. and Pemberton, D.J. (1990) Fibrocartilage in the attachment zones of the quadriceps tendon and patellar ligament of man. J Anat 171, 155-162, PubMed: 2081702

25 Benjamin, M. et al. (1991) Quantitative differences in the histology of the attachment zones of the meniscal horns in the knee joint of man. J Anat 177, 127-134, PubMed: 1769887

26 Schweitzer, R. et al. (2001) Analysis of the tendon cell fate using Scleraxis, a specific marker for tendons and ligaments. Development 128, 38553866, PubMed: 11585810

27 Salingcarnboriboon, R. et al. (2003) Establishment of tendon-derived cell lines exhibiting pluripotent mesenchymal stem celllike property. Exp Cell Res 287, 289-300, PubMed: 12837285

28 Banes, A.J. et al. (1988) Cell populations of tendon: a simplified method for isolation of synovial cells and internal fibroblasts: confirmation of origin and biologic properties. J Orthop Res 6, 83-94, PubMed: 3334741

29 Gelberman, R.H. et al. (1986) Flexor tendon repair. J Orthop Res 4, 119-128, PubMed: 3950804

30 Garner, W.L. et al. (1989) Identification of the collagen-producing cells in healing flexor tendons. Plast Reconstr Surg 83, 875-879, PubMed: 2652163

31 Gelberman, R.H. et al. (1991) Fibroblast chemotaxis after tendon repair. J Hand Surg [Am] 16, 686-693, PubMed: 1880367

32 Khan, U., Edwards, J.C. and McGrouther, D.A. (1996) Patterns of cellular activation after tendon injury. J Hand Surg [Br] 21, 813-820, PubMed: 8982936

33 Vogel, K.G. et al. (1986) Proteoglycan synthesis 
by fibroblast cultures initiated from regions of adult bovine tendon subjected to different mechanical forces. Eur J Cell Biol 41, 102-112, PubMed: 3792332

34 Koob, T.J. et al. (1992) Compression loading in vitro regulates proteoglycan synthesis by tendon fibrocartilage. Arch Biochem Biophys 298, 303312, PubMed: 1524441

35 Evanko, S.P. and Vogel, K.G. (1993) Proteoglycan synthesis in fetal tendon is differentially regulated by cyclic compression in vitro. Arch Biochem Biophys 307, 153-164, PubMed: 7694546

36 Vailas, A.C. et al. (1978) Physical activity and hypophysectomy on the aerobic capacity of ligaments and tendons. J Appl Physiol 44, 542546, PubMed: 205528

37 Robbins, J.R. and Vogel, K.G. (1994) Regional expression of mRNA for proteoglycans and collagen in tendon. Eur J Cell Biol 64, 264-270, PubMed: 7813514

38 Riley, G.P. et al. (2002) Matrix metalloproteinase activities and their relationship with collagen remodelling in tendon pathology. Matrix Biol 21, 185-195, PubMed: 11852234

39 Brown, J.C. and Timpl, R. (1995) The collagen superfamily. Int Arch Allergy Immunol 107, 484490, PubMed: 7620364

40 Aumailley, M. and Gayraud, B. (1998) Structure and biological activity of the extracellular matrix. J Mol Med 76, 253-265, PubMed: 9535559

41 Prockop, D.J. and Kivirikko, K.I. (1995) Collagens: molecular biology, diseases, and potentials for therapy. Annu Rev Biochem 64, 403-434, PubMed: 7574488

42 Myllyharju, J. and Kivirikko, K.I. (2001) Collagens and collagen-related diseases. Ann Med 33, 7-21, PubMed: 11310942

43 Gelse, K., Poschl, E. and Aigner, T. (2003) Collagens-structure, function, and biosynthesis. Adv Drug Deliv Rev 55, 1531-1546, PubMed: 14623400

44 Myllyharju, J. and Kivirikko, K.I. (2004) Collagens, modifying enzymes and their mutations in humans, flies and worms. Trends Genet 20, 33-43, PubMed: 14698617

45 Koch, M. et al. (2003) Collagen XXIV, a vertebrate fibrillar collagen with structural features of invertebrate collagens: selective expression in developing cornea and bone. J Biol Chem 278, 43236-43244, PubMed: 12874293

46 Boot-Handford, R.P. et al. (2003) A novel and highly conserved collagen (pro(alpha)1(XXVII)) with a unique expression pattern and unusual molecular characteristics establishes a new clade within the vertebrate fibrillar collagen family. J Biol Chem 278, 31067-31077, PubMed: 12766169

47 Riley, G.P. et al. (1994) Tendon degeneration and chronic shoulder pain: changes in the collagen composition of the human rotator cuff tendons in rotator cuff tendinitis. Ann Rheum Dis 53, 359366, PubMed: 8037494

48 Duance, V.C. et al. (1977) The location of three collagen types in skeletal muscle. FEBS Lett 79, 248-252, PubMed: 330230

49 Kumagai, J., Sarkar, K. and Uhthoff, H.K. (1994) The collagen types in the attachment zone of rotator cuff tendons in the elderly: an immunohistochemical study. J Rheumatol 21, 2096-2100, PubMed: 7869316

50 Fukuta, S. et al. (1998) Identification of types II, IX and $X$ collagens at the insertion site of the bovine achilles tendon. Matrix Biol 17, 65-73, PubMed: 9628253

51 Sagarriga Visconti, C.S. et al. (1996) Biochemical analysis of collagens at the ligament-bone interface reveals presence of cartilage-specific collagens. Arch Biochem Biophys 135-142, PubMed: 8638922

52 Iozzo, R.V. and Murdoch, A.D. (1996) Proteoglycans of the extracellular environment: clues from the gene and protein side offer novel perspectives in molecular diversity and function. Faseb J 10, 598-614, PubMed: 8621059

53 Iozzo, R.V. (1999) The biology of the small leucine-rich proteoglycans. Functional network of interactive proteins. J Biol Chem 274, 1884318846, PubMed: 10383378

54 Scott, J.E. (1990) Proteoglycan:collagen interactions and subfibrillar structure in collagen fibrils. Implications in the development and ageing of connective tissues. J Anat 169, 23-35, PubMed: 2384335

55 Hardingham, T.E. and Fosang, A.J. (1992) Proteoglycans: many forms and many functions. Faseb J 6, 861-870, PubMed: 1740236

56 Iozzo, R.V. (1998) Matrix proteoglycans: from molecular design to cellular function. Annu Rev Biochem 67, 609-652, PubMed: 9759499

57 Vogel, K.G. and Heinegard, D. (1985) Characterization of proteoglycans from adult bovine tendon. J Biol Chem 260, 9298-9306, PubMed: 4019475

58 Ameye, L. et al. (2002) Abnormal collagen fibrils in tendons of biglycan/fibromodulin-deficient mice lead to gait impairment, ectopic ossification, and osteoarthritis. Faseb J 16, 673- 
680, PubMed: 11978731

59 Ameye, L. and Young, M.F. (2002) Mice deficient in small leucine-rich proteoglycans: novel in vivo models for osteoporosis, osteoarthritis, EhlersDanlos syndrome, muscular dystrophy, and corneal diseases. Glycobiology 12, 107R-116R, PubMed: 12213783

60 Scott, J.E., Orford, C.R. and Hughes, E.W. (1981)

Proteoglycan-collagen arrangements in developing rat tail tendon. An electron microscopical and biochemical investigation. Biochem J 195, 573-581, PubMed: 6459082

61 Hedbom, E. and Heinegard, D. (1993) Binding of fibromodulin and decorin to separate sites on fibrillar collagens. J Biol Chem 268, 27307-27312, PubMed: 8262971

62 Nakamura, N. et al. (2000) Decorin antisense gene therapy improves functional healing of early rabbit ligament scar with enhanced collagen fibrillogenesis in vivo. J Orthop Res 18, 517-523, PubMed: 11052486

63 Wiberg, C. et al. (2002) Biglycan organizes collagen VI into hexagonal-like networks resembling tissue structures. J Biol Chem 277, 49120-49126, PubMed: 12354766

64 Ruoslahti, E. et al. (1992) Extracellular matrix/ growth factor interactions. Cold Spring Harb Symp Quant Biol 57, 309-315, PubMed: 1339667

65 Hildebrand, A. et al. (1994) Interaction of the small interstitial proteoglycans biglycan, decorin and fibromodulin with transforming growth factor beta. Biochem J 302 ( Pt 2), 527-534, PubMed: 8093006

66 Schlessinger, J., Lax, I. and Lemmon, M. (1995) Regulation of growth factor activation by proteoglycans: what is the role of the low affinity receptors? Cell 83, 357-360, PubMed: 8521464

67 Hardingham, T.E. and Fosang, A.J. (1995) The structure of aggrecan and its turnover in cartilage. J Rheumatol Suppl 43, 86-90, PubMed: 7752148

68 Margolis, R.U. and Margolis, R.K. (1994) Aggrecan-versican-neurocan family proteoglycans. Methods Enzymol 245, 105-126, PubMed: 7539091

69 Elliott, D.H. (1965) Structure and Function of Mammalian Tendon. Biol Rev Camb Philos Soc 40, 392-421, PubMed: 14340913

70 Ramirez, F. and Pereira, L. (1999) The fibrillins. Int J Biochem Cell Biol 31, 255-259, PubMed: 10216958

71 Bax, D.V. et al. (2003) Cell adhesion to fibrillin-1 molecules and microfibrils is mediated by alpha
5 beta 1 and alpha v beta 3 integrins. J Biol Chem 278, 34605-34616, PubMed: 12807887

72 Dietz, H.C. et al. (1991) Marfan syndrome caused by a recurrent de novo missense mutation in the fibrillin gene. Nature 352, 337-339, PubMed: 1852208

73 Reinhardt, D.P. et al. (1996) Fibrillin-1 and fibulin-2 interact and are colocalized in some tissues. J Biol Chem 271, 19489-19496, PubMed: 8702639

74 Kassner, A. et al. (2003) Discrete integration of collagen XVI into tissue-specific collagen fibrils or beaded microfibrils. Matrix Biol 22, 131-143, PubMed: 12782140

75 Visconti, R.P. et al. (2003) Codistribution analysis of elastin and related fibrillar proteins in early vertebrate development. Matrix Biol 22, 109-121, PubMed: 12782138

76 Timpl, R. et al. (2003) Fibulins: a versatile family of extracellular matrix proteins. Nat Rev Mol Cell Biol 4, 479-489, PubMed: 12778127

77 Ritty, T.M., Ditsios, K. and Starcher, B.C. (2002) Distribution of the elastic fiber and associated proteins in flexor tendon reflects function. Anat Rec 268, 430-440, PubMed: 12420291

78 Labat-Robert, J., Bihari-Varga, M. and Robert, L. (1990) Extracellular matrix. FEBS Lett 268, 386393, PubMed: 2166694

79 Jozsa, L. et al. (1989) Fibronectin and laminin in Achilles tendon. Acta Orthop Scand 60, 469-471, PubMed: 2683566

80 Lehto, M. et al. (1990) Fibronectin in the ruptured human Achilles tendon and its paratenon. An immunoperoxidase study. Ann Chir Gynaecol 79, 72-77, PubMed: 2201247

81 Amiel, D. et al. (1991) Fibronectin in healing flexor tendons subjected to immobilization or early controlled passive motion. Matrix 11, 184189, PubMed: 1870449

82 Chiquet, M. (1992) Tenascin: an extracellular matrix protein involved in morphogenesis of epithelial organs. Kidney Int 41, 629-631, PubMed: 1374137

83 Gulcher, J.R. et al. (1991) Structure of the human hexabrachion (tenascin) gene. Proc Natl Acad Sci U S A 88, 9438-9442, PubMed: 1719530

84 Riley, G.P. et al. (1996) Tenascin-C and human tendon degeneration. Am J Pathol 149, 933-943, PubMed: 8780397

85 Mackie, E.J., Halfter, W. and Liverani, D. (1988) Induction of tenascin in healing wounds. J Cell Biol 107, 2757-2767, PubMed: 2462568

86 Whitby, D.J. and Ferguson, M.W. (1991) The 
extracellular matrix of lip wounds in fetal, neonatal and adult mice. Development 112, 651668, PubMed: 1724421

87 DiCesare, P. et al. (1994) Cartilage oligomeric matrix protein (COMP) is an abundant component of tendon. FEBS Lett 354, 237-240, PubMed: 7957930

88 Oldberg, A. et al. (1992) COMP (cartilage oligomeric matrix protein) is structurally related to the thrombospondins. J Biol Chem 267, 2234622350, PubMed: 1429587

89 Smith, R.K. et al. (1997) The distribution of cartilage oligomeric matrix protein (COMP) in tendon and its variation with tendon site, age and load. Matrix Biol 16, 255-271, PubMed: 9501326

90 Briggs, M.D. et al. (1995) Pseudoachondroplasia and multiple epiphyseal dysplasia due to mutations in the cartilage oligomeric matrix protein gene. Nat Genet 10, 330-336, PubMed: 7670472

91 Oldberg, A. et al. (1990) Structure and function of extracellular matrix proteoglycans. Biochem Soc Trans 18, 789-792, PubMed: 2083676

92 Sage, E.H. and Bornstein, P. (1991) Extracellular proteins that modulate cell-matrix interactions. SPARC, tenascin, and thrombospondin. J Biol Chem 266, 14831-14834, PubMed: 1714444

93 Bornstein, P. (1992) Thrombospondins: structure and regulation of expression. Faseb J 6, 32903299, PubMed: 1426766

94 Miller, R.R. and McDevitt, C.A. (1991) Thrombospondin in ligament, meniscus and intervertebral disc. Biochim Biophys Acta 1115, 85-88, PubMed: 1958708

95 Tallon, C., Maffulli, N. and Ewen, S.W. (2001) Ruptured Achilles tendons are significantly more degenerated than tendinopathic tendons. Med Sci Sports Exerc 33, 1983-1990, PubMed: 11740288

96 Chard, M.D., Gresham, A. and Hazleman, B.L. (1989) Age-related changes in the rotator cuff. Br J Rheum 28, 19 (Abstract)

97 Bank, R.A. et al. (1999) Lysylhydroxylation and non-reducible crosslinking of human supraspinatus tendon collagen: changes with age and in chronic rotator cuff tendinitis. Ann Rheum Dis 58, 35-41, PubMed: 10343538

98 Bailey, A.J. et al. (1975) Characterization of the collagen of human hypertrophic and normal scars. Biochim Biophys Acta 405, 412-421, PubMed: 1180964

99 Eriksen, H.A. et al. (2002) Increased content of type III collagen at the rupture site of human
Achilles tendon. J Orthop Res 20, 1352-1357, PubMed: 12472252

100 Goncalves-Neto, J. et al. (2002) Changes in collagen matrix composition in human posterior tibial tendon dysfunction. Joint Bone Spine 69, 189-194, PubMed: 12027311

101 Lapiere, C.M., Nusgens, B. and Pierard, G.E. (1977) Interaction between collagen type I and type III in conditioning bundles organization. Connect Tissue Res 5, 21-29, PubMed: 141359

102 Magnusson, S.P. et al. (2002) Collagen fibril size and crimp morphology in ruptured and intact Achilles tendons. Matrix Biol 21, 369-377, PubMed: 12128074

103 Riley, G.P. et al. (1994) Glycosaminoglycans of human rotator cuff tendons: changes with age and in chronic rotator cuff tendinitis. Ann Rheum Dis 53, 367-376, PubMed: 8037495

104 Birch, H.L., Bailey, A.J. and Goodship, A.E. (1998) Macroscopic 'degeneration' of equine superficial digital flexor tendon is accompanied by a change in extracellular matrix composition. Equine Vet J 30, 534-539, PubMed: 9844973

105 Maffulli, N., Waterston, S.W. and Ewen, S.W. (2002) Ruptured Achilles tendons show increased lectin stainability. Med Sci Sports Exerc 34, 10571064, PubMed: 12131241

106 Tillander, B., Franzen, L. and Norlin, R. (2002) Fibronectin, MMP-1 and histologic changes in rotator cuff disease. J Orthop Res 20, 1358-1364, PubMed: 12472253

107 Ireland, D. et al. (2001) Multiple changes in gene expression in chronic human Achilles tendinopathy. Matrix Biol 20, 159-169, PubMed: 11420148

108 Alfredson, H. et al. (2003) cDNA-arrays and realtime quantitative PCR techniques in the investigation of chronic Achilles tendinosis. J Orthop Res 21, 970-975, PubMed: 14554207

109 Corps, A.N. et al. (2004) Versican splice variant messenger RNA expression in normal human Achilles tendon and tendinopathies. Rheumatology (Oxford) 43, 969-972, PubMed: 15138331

110 Alfredson, H. et al. (2001) In vivo microdialysis and immunohistochemical analyses of tendon tissue demonstrated high amounts of free glutamate and glutamate NMDAR1 receptors, but no signs of inflammation, in Jumper's knee. J Orthop Res 19, 881-886, PubMed: 11562137

111 Everts, V. et al. (1996) Phagocytosis and intracellular digestion of collagen, its role in turnover and remodelling. Histochem J 28, 229- 
245, PubMed: 8762055

112 Creemers, L.B. et al. (1998) Gelatinase A (MMP-2) and cysteine proteinases are essential for the degradation of collagen in soft connective tissue. Matrix Biol 17, 35-46, PubMed: 9628251

113 Matrisian, L.M. (1990) Metalloproteinases and their inhibitors in matrix remodeling. Trends Genet 6, 121-125, PubMed: 2132731

114 Nagase, H. (1994) Matrix metalloproteinases. A mini-review. Contrib Nephrol 107, 85-93, PubMed: 8004978

115 Murphy, G. et al. (1994) Regulation of matrix metalloproteinase activity. Ann N Y Acad Sci 732, 31-41, PubMed: 7978800

116 Cawston, T.E. (1995) Proteinases and inhibitors. Br Med Bull 51, 385-401, PubMed: 7552071

117 Birkedal-Hansen, H. (1995) Proteolytic remodeling of extracellular matrix. Curr Opin Cell Biol 7, 728-735, PubMed: 8573349

118 Clark, I.M. and Parker, A.E. (2003) Metalloproteinases: their role in arthritis and potential as therapeutic targets. Expert Opin Ther Targets 7, 19-34, PubMed: 12556200

119 McCawley, L.J. and Matrisian, L.M. (2001) Matrix metalloproteinases: they're not just for matrix anymore! Curr Opin Cell Biol 13, 534-540, PubMed: 11544020

120 Lafleur, M.A., Handsley, M.M. and Edwards, D.R. (2003) Metalloproteinases and their inhibitors in angiogenesis. Expert Rev Mol Med 2003, 1-39, PubMed: 14585170

121 Murphy, G. and Willenbrock, F. (1995) Tissue inhibitors of matrix metalloendopeptidases. Methods Enzymol 248, 496-510, PubMed: 7674941

122 Vater, C.A., Mainardi, C.L. and Harris, E.D., Jr. (1979) Inhibitor of human collagenase from cultures of human tendon. J Biol Chem 254, 30453053, PubMed: 218961

123 Porat, S. et al. (1985) Increased collagenolytic activity in severed and sutured tendons following topical application of exogenous collagen in chickens. J Orthop Res 3, 43-48, PubMed: 2984391

124 Piening, C. and Riederer-Henderson, M.A. (1989) Neutral metalloprotease from tendons. J Orthop Res 7, 228-234, PubMed: 2537397

125 Harper, J., Amiel, D. and Harper, E. (1988) Collagenase production by rabbit ligaments and tendon. Connect Tissue Res 17, 253-259, PubMed: 2850134

126 Harper, J., Amiel, D. and Harper, E. (1989) Collagenases from periarticular ligaments and tendon: enzyme levels during the development of joint contracture. Matrix 9, 200-205, PubMed: 2550751

127 Harper, J., Amiel, D. and Harper, E. (1992) Inhibitors of collagenase in ligaments and tendons of rabbits immobilized for 4 weeks. Connect Tissue Res 28, 257-261, PubMed: 1304441

128 Amiel, D. et al. (1983) Stress deprivation effect on metabolic turnover of the medial collateral ligament collagen. A comparison between nineand 12-week immobilization. Clin Orthop 265270, PubMed: 6821994

129 Akeson, W.H. et al. (1987) Effects of immobilization on joints. Clin Orthop 28-37, PubMed: 3581580

130 Majima, T. et al. (2000) In-vitro cyclic tensile loading of an immobilized and mobilized ligament autograft selectively inhibits mRNA levels for collagenase (MMP-1). J Orthop Sci 5, 503-510, PubMed: 11180909

131 Arnoczky, S.P. et al. (2004) Ex vivo static tensile loading inhibits MMP-1 expression in rat tail tendon cells through a cytoskeletally based mechanotransduction mechanism. J Orthop Res 22, 328-333, PubMed: 15013092

132 Arnoczky, S.P. et al. (2002) Activation of stressactivated protein kinases (SAPK) in tendon cells following cyclic strain: the effects of strain frequency, strain magnitude, and cytosolic calcium. J Orthop Res 20, 947-952, PubMed: 12382958

133 Lavagnino, M. et al. (2003) Effect of amplitude and frequency of cyclic tensile strain on the inhibition of MMP-1 mRNA expression in tendon cells: an in vitro study. Connect Tissue Res 44, 181-187, PubMed: 14504039

134 Cawston, T.E. et al. (1998) The role of oncostatin $\mathrm{M}$ in animal and human connective tissue collagen turnover and its localization within the rheumatoid joint. Arthritis Rheum 41, 1760-1771, PubMed: 9778217

135 Archambault, J.M. et al. (2002) Rabbit tendon cells produce MMP-3 in response to fluid flow without significant calcium transients. J Biomech 35, 303-309, PubMed: 11858805

136 Archambault, J. et al. (2002) Stretch and interleukin-1beta induce matrix metalloproteinases in rabbit tendon cells in vitro. J Orthop Res 20, 36-39, PubMed: 11853088

137 Archambault, J.M., Hart, D.A. and Herzog, W. (2001) Response of rabbit Achilles tendon to chronic repetitive loading. Connect Tissue Res 42, 13-23, PubMed: 11696985 
138 Koskinen, S.O. et al. (2004) Physical exercise can influence local levels of matrix metalloproteinases and their inhibitors in tendon-related connective tissue. J Appl Physiol 96, 861-864, PubMed: 14506093

139 Oshiro, W. et al. (2003) Flexor tendon healing in the rat: a histologic and gene expression study. J Hand Surg [Am] 28, 814-823, PubMed: 14507513

140 Yoshihara, Y. et al. (2001) Biochemical markers in the synovial fluid of glenohumeral joints from patients with rotator cuff tear. J Orthop Res 19, 573-579, PubMed: 11518264

141 Gotoh, M. et al. (1997) Significance of granulation tissue in torn supraspinatus insertions: an immunohistochemical study with antibodies against interleukin-1 beta, cathepsin $\mathrm{D}$, and matrix metalloprotease-1. J Orthop Res 15, 33-39, PubMed: 9066524

142 Sandy, J.D. et al. (1991) Catabolism of aggrecan in cartilage explants. Identification of a major cleavage site within the interglobular domain. J Biol Chem 266, 8683-8685, PubMed: 2026585

143 Sandy, J.D. et al. (1992) The structure of aggrecan fragments in human synovial fluid. Evidence for the involvement in osteoarthritis of a novel proteinase which cleaves the Glu 373-Ala 374 bond of the interglobular domain. J Clin Invest 89, 1512-1516, PubMed: 1569188

144 Kaushal, G.P. and Shah, S.V. (2000) The new kids on the block: ADAMTSs, potentially multifunctional metalloproteinases of the ADAM family. J Clin Invest 105, 1335-1337, PubMed: 10811839

145 Cal, S. et al. (2002) Cloning, expression analysis, and structural characterization of seven novel human ADAMTSs, a family of metalloproteinases with disintegrin and thrombospondin-1 domains. Gene 283, 49-62, PubMed: 11867212

146 Colige, A. et al. (1999) Human Ehlers-Danlos syndrome type VII C and bovine dermatosparaxis are caused by mutations in the procollagen I N-proteinase gene. Am J Hum Genet 65, 308-317, PubMed: 10417273

147 Fernandes, R.J. et al. (2001) Procollagen II amino propeptide processing by ADAMTS-3. Insights on dermatosparaxis. J Biol Chem 276, 3150231509, PubMed: 11408482

148 Colige, A. et al. (2002) Cloning and characterization of ADAMTS-14, a novel ADAMTS displaying high homology with ADAMTS-2 and ADAMTS-3. J Biol Chem 277, 5756-5766, PubMed: 11741898
149 Tortorella, M.D. et al. (1999) Purification and cloning of aggrecanase-1: a member of the ADAMTS family of proteins. Science 284, 16641666, PubMed: 10356395

150 Abbaszade, I. et al. (1999) Cloning and characterization of ADAMTS11, an aggrecanase from the ADAMTS family. J Biol Chem 274, 23443-23450, PubMed: 10438522

151 Kuno, K. et al. (2000) ADAMTS-1 cleaves a cartilage proteoglycan, aggrecan. FEBS Lett 478, 241-245, PubMed: 10930576

152 Somerville, R.P. et al. (2003) Characterization of ADAMTS-9 and ADAMTS-20 as a distinct ADAMTS subfamily related to Caenorhabditis elegans GON-1. J Biol Chem 278, 9503-9513, PubMed: 12514189

153 Yamaji, N. et al. (2001) Novel metalloprotease having aggrecanase activity. Patent WO0134785

154 Collins-Racie, L.A. et al. (2004) ADAMTS-8 exhibits aggrecanase activity and is expressed in human articular cartilage. Matrix Biol 23, 219230, PubMed: 15296936

155 Sandy, J.D. et al. (2001) Versican V1 proteolysis in human aorta in vivo occurs at the Glu441-Ala442 bond, a site that is cleaved by recombinant ADAMTS-1 and ADAMTS-4. J Biol Chem 276, 13372-13378, PubMed: 11278559

156 Dickinson, S.C. et al. (2003) Cleavage of cartilage oligomeric matrix protein (thrombospondin-5) by matrix metalloproteinases and a disintegrin and metalloproteinase with thrombospondin motifs. Matrix Biol 22, 267-278, PubMed: 12853037

157 Tortorella, M.D. et al. (2001) The role of ADAMTS4 (aggrecanase-1) and ADAM-TS5 (aggrecanase-2) in a model of cartilage degradation. Osteoarthritis Cartilage 9, 539-552, PubMed: 11520168

158 Caterson, B. et al. (1999) Mechanisms of proteoglycan metabolism that lead to cartilage destruction in the pathogenesis of arthritis. Drugs Today (Barc) 35, 397-402, PubMed: 12973442

159 Vankemmelbeke, M.N. et al. (2001) Expression and activity of ADAMTS-5 in synovium. Eur J Biochem 268, 1259-1268, PubMed: 11231277

160 Koshy, P.J. et al. (2002) The modulation of matrix metalloproteinase and ADAM gene expression in human chondrocytes by interleukin-1 and oncostatin M: a time-course study using realtime quantitative reverse transcriptionpolymerase chain reaction. Arthritis Rheum 46, 961-967, PubMed: 11953973 
161 Tsuzaki, M. et al. (2003) IL-1 beta induces COX2, MMP-1, -3 and -13, ADAMTS-4, IL-1 beta and IL6 in human tendon cells. J Orthop Res 21, 256264, PubMed: 12568957

162 Flannery, C.R. et al. (2002) Autocatalytic cleavage of ADAMTS-4 (Aggrecanase-1) reveals multiple glycosaminoglycan-binding sites. J Biol Chem 277, 42775-42780, PubMed: 12202483

163 Kashiwagi, M. et al. (2004) Altered proteolytic activities of ADAMTS-4 expressed by C-terminal processing. J Biol Chem 279, 10109-10119, PubMed: 14662755

164 Wang, P. et al. (2004) Proprotein convertase furin interacts with and cleaves pro-ADAMTS4 (Aggrecanase-1) in the trans-Golgi network. J Biol Chem 279, 15434-15440, PubMed: 14744861

165 Gao, G. et al. (2004) ADAMTS4 (aggrecanase-1) activation on the cell surface involves C-terminal cleavage by glycosylphosphatidyl inositolanchored membrane type 4-matrix metalloproteinase and binding of the activated proteinase to chondroitin sulfate and heparan sulfate on syndecan-1. J Biol Chem 279, 1004210051, PubMed: 14701864

166 Kashiwagi, M. et al. (2001) TIMP-3 is a potent inhibitor of aggrecanase 1 (ADAM-TS4) and aggrecanase 2 (ADAM-TS5). J Biol Chem 276, 12501-12504, PubMed: 11278243

167 Rees, S.G. et al. (2000) Catabolism of aggrecan, decorin and biglycan in tendon. Biochem J $350 \mathrm{Pt}$ 1, 181-188, PubMed: 10926842

168 Samiric, T., Ilic, M.Z. and Handley, C.J. (2004) Characterisation of proteoglycans and their catabolic products in tendon and explant cultures of tendon. Matrix Biol 23, 127-140, PubMed: 15246111

169 Samiric, T., Ilic, M.Z. and Handley, C.J. (2004) Large aggregating and small leucine-rich proteoglycans are degraded by different pathways and at different rates in tendon. Eur J Biochem 271, 3612-3620, PubMed: 15317597

170 Attur, M.G. et al. (2002) Osteoarthritis or osteoarthrosis: the definition of inflammation becomes a semantic issue in the genomic era of molecular medicine. Osteoarthritis Cartilage 10, 1-4, PubMed: 11795977

171 Abramson, S.P. et al. (2001) Nitric oxide and inflammatory mediators in the perpetuation of osteoarthritis. Curr Rheumatol Rep 3, 535-541, PubMed: 11709117

172 Amin, A.R. et al. (2000) COX-2, NO, and cartilage damage and repair. Curr Rheumatol Rep 2, 447-453, PubMed: 11123096
173 Gotoh, M. et al. (2000) Perforation of rotator cuff increases interleukin 1beta production in the synovium of glenohumeral joint in rotator cuff diseases. J Rheumatol 27, 2886-2892, PubMed: 11128681

174 Gotoh, M. et al. (2001) Interleukin-1-induced subacromial synovitis and shoulder pain in rotator cuff diseases. Rheumatology (Oxford) 40, 995-1001, PubMed: 11561109

$175 \mathrm{Fu}$, S.C. et al. (2002) Increased expression of transforming growth factor-beta1 in patellar tendinosis. Clin Orthop 174-183, PubMed: 12072760

176 Hosaka, Y. et al. (2002) Localization of cytokines in tendinocytes of the superficial digital flexor tendon in the horse. J Vet Med Sci 64, 945-947, PubMed: 12419874

177 Kjaer, M. et al. (2000) In vivo studies of peritendinous tissue in exercise. Scand J Med Sci Sports 10, 326-331, PubMed: 11085559

178 Langberg, H. et al. (2002) Exercise-induced increase in interstitial bradykinin and adenosine concentrations in skeletal muscle and peritendinous tissue in humans. J Physiol 542, 977-983, PubMed: 12154194

179 Langberg, H. et al. (2002) Substantial elevation of interleukin- 6 concentration in peritendinous tissue, in contrast to muscle, following prolonged exercise in humans. J Physiol 542, 985-990, PubMed: 12154195

180 Tsuzaki, M. et al. (2003) ATP modulates loadinducible IL-1beta, COX 2, and MMP-3 gene expression in human tendon cells. J Cell Biochem 89, 556-562, PubMed: 12761889

181 Wang, J.H. et al. (2003) Cyclic mechanical stretching of human tendon fibroblasts increases the production of prostaglandin E2 and levels of cyclooxygenase expression: a novel in vitro model study. Connect Tissue Res 44, 128-133, PubMed: 14504032

182 Wang, J.H. et al. (2004) Repetitively stretched tendon fibroblasts produce inflammatory mediators. Clin Orthop 243-250, PubMed: 15187863

$183 \mathrm{Li}, \mathrm{Z}$. et al. (2004) Inflammatory response of human tendon fibroblasts to cyclic mechanical stretching. Am J Sports Med 32, 435-440,

PubMed: 14977670

184 Alfredson, H., Thorsen, K. and Lorentzon, R. (1999) In situ microdialysis in tendon tissue: high levels of glutamate, but not prostaglandin E2 in chronic Achilles tendon pain. Knee Surg Sports Traumatol Arthrosc 7, 378-381, PubMed: 
10639657

185 Alfredson, H. and Lorentzon, R. (2002) Chronic tendon pain: no signs of chemical inflammation but high concentrations of the neurotransmitter glutamate. Implications for treatment? Curr Drug Targets 3, 43-54, PubMed: 11899264

186 Cawston, T.E. and Rowan, A. (1998) Prevention of cartilage breakdown by matrix metalloproteinase inhibition-a realistic therapeutic target? Br J Rheumatol 37, 353-356, PubMed: 9619881

187 Whittaker, M. et al. (1999) Design and therapeutic application of matrix metalloproteinase inhibitors. Chem Rev 99, 27352776, PubMed: 11749499

188 Drummond, A.H. et al. (1999) Preclinical and clinical studies of MMP inhibitors in cancer. Ann N Y Acad Sci 878, 228-235, PubMed: 10415734

189 Brown, M.F. et al. (1997) Sensory and sympathetic innervation of the vertebral endplate in patients with degenerative disc disease. J Bone Joint Surg Br 79, 147-153, PubMed: 9020464

190 Freemont, A.J. et al. (1997) Nerve ingrowth into diseased intervertebral disc in chronic back pain. Lancet 350, 178-181, PubMed: 9250186

191 Sanchis-Alfonso, V., Rosello-Sastre, E. and Subias-Lopez, A. (2001) Neuroanatomic basis for pain in patellar tendinosis ("jumper's knee"): a neuroimmunohistochemical study. Am J Knee Surg 14, 174-177, PubMed: 11491428

192 Alfredson, H. et al. (2000) In vivo investigation of ECRB tendons with microdialysis technique-no signs of inflammation but high amounts of glutamate in tennis elbow. Acta Orthop Scand 71 475-479, PubMed: 11186404

193 Alfredson, H. et al. (2001) Glutamate NMDAR1 receptors localised to nerves in human Achilles tendons. Implications for treatment? Knee Surg Sports Traumatol Arthrosc 9, 123-126, PubMed: 11354854

194 Gotoh, M. et al. (1998) Increased substance P in subacromial bursa and shoulder pain in rotator cuff diseases. J Orthop Res 16, 618-621, PubMed: 9820287

195 Hart, D.A., Kydd, A. and Reno, C. (1999) Gender and pregnancy affect neuropeptide responses of the rabbit Achilles tendon. Clin Orthop 237-246, PubMed: 10627708

196 Hart, D.A. et al. (1998) Gender and neurogenic variables in tendon biology and repetitive motion disorders. Clin Orthop 44-56, PubMed: 9646746

197 Hart, D.A., Frank, C.B. and R.C., B. (1995) Inflammatory processes in repetitive motion and overuse syndromes:potential role of neurogenic mechanisms in tendons and ligaments. In Repetitive Motion Disorders of the Upper Extremity (Gordon, S.L., Blair, S.J. and Fine, L.J., eds), pp. 247-262, American Academy of Orthopaedic Surgeons, Rosemont, IL

198 Hart, D.A. and Reno, C. (1998) Pregnancy alters the in vitro responsiveness of the rabbit medial collateral ligament to neuropeptides: effect on mRNA levels for growth factors, cytokines, iNOS, COX-2, metalloproteinases and TIMPs. Biochim Biophys Acta 1408, 35-43, PubMed: 9784599 


\section{Further reading, resources and contacts}

\section{Tendon structure and function}

Kannus, P. (2000) Structure of the tendon connective tissue. Scand J Med Sci Sports 10, 312-320, PubMed: 11085557

Benjamin, M. (2004) The structure and function of tendons. In Soft Tissue Rheumatology (Hazleman, B.L., Riley, G.P. and Speed, C.A., eds), pp. 9-19, Oxford University Press, Oxford

Oakes, B. (1994) Tendon-ligament basic science. In Oxford Textbook of Medicine (Harries, M. et al., eds), pp. 493-511, Oxford University Press, Oxford

\section{Tendon pathology}

Kannus, P. (1997) Etiology and pathophysiology of chronic tendon disorders in sports. Scand J Med Sci Sports 7, 78-85, PubMed: 9211608

Józsa, L. and Kannus, P. (1997) Overuse injuries of tendons. In Human Tendons: Anatomy, Physiology and Pathology (Józsa, L. and Kannus, P., eds), pp. 164-253, Champaign, IL

Riley, G. (2004) The pathogenesis of tendinopathy. A molecular perspective. Rheumatology (Oxford) 43, 131-142, PubMed: 12867575

Riley, G.P. (2004) Tendon and ligament biochemistry and pathology. In Soft Tissue Rheumatology (Hazleman, B.L., Riley, G.P. and Speed, C.A., eds), pp. 20-53, Oxford University Press, Oxford

Leadbetter, W.B. (1992) Cell-matrix response in tendon injury. Clin Sports Med 11, 533-578, PubMed: 1638640

\section{Treatment of tendinopathy}

Almekinders, L.C. and Temple, J.D. (1998) Etiology, diagnosis, and treatment of tendonitis: an analysis of the literature. Med Sci Sports Exerc 30, 1183-1190, PubMed: 9710855

el Hawary, R., Stanish, W.D. and Curwin, S.L. (1997) Rehabilitation of tendon injuries in sport. Sports Med 24, 347-358, PubMed: 9368280

\section{Collagen}

Myllyharju, J. and Kivirikko, K.I. (2004) Collagens, modifying enzymes and their mutations in humans, flies and worms. Trends Genet 20, 33-43, PubMed: 14698617

\section{Proteoglycan}

lozzo, R.V. (1998) Matrix proteoglycans: from molecular design to cellular function. Annu Rev Biochem 67, 609-652, PubMed: 9759499

\section{Extracellular matrix in general}

Aumailley, M. and Gayraud, B. (1998) Structure and biological activity of the extracellular matrix. J Mol Med 76, 253-265, PubMed: 9535559

\section{Matrix metalloproteinases}

Clark, I.M. and Parker, A.E. (2003) Metalloproteinases: their role in arthritis and potential as therapeutic targets. Expert Opin Ther Targets 7, 19-34, PubMed: 12556200

McCawley, L.J. and Matrisian, L.M. (2001) Matrix metalloproteinases: they're not just for matrix anymore! Curr Opin Cell Biol 13, 534-540, PubMed: 11544020

\section{Aggrecanases}

Apte, S.S. (2004) A disintegrin-like and metalloprotease (reprolysin type) with thrombospondin type 1 motifs: the ADAMTS family. Int J Biochem Cell Biol 36, 981-985, PubMed: 15094112

Recent related article in Expert Reviews in Molecular Medicine:

Lafleur, M.A., Handsley, M.M. and Edwards, D.R. (2003) Metalloproteinases and their inhibitors in angiogenesis. Expert Rev Mol Med 5(23), 1-39, PubMed: 14585170 


\section{Figures}

Figure 1. Structure of tendon.

Figure 2. Synthesis of a fibril-forming collagen.

Figure 3. Proteoglycans in tendon.

Figure 4. Histopathology of tendinopathy.

Figure 5. Domain structure of matrix metalloproteinases (MMPs) and ADAMTS.

\section{Table}

Table 1. Molecular composition of tendon extracellular matrix.

Table 2. Major known or putative substrates of the matrix metalloproteinases.

\section{Citation details for this article}

Graham Riley (2005) Chronic tendon pathology: molecular basis and therapeutic implications. Expert Rev. Mol. Med. Vol. 7, Issue 5, 24 March, DOI: 10.1017/S1462399405008963 